\title{
The Study of Track and Field Athletes Ankle-joint Injury Reasons and Preventive Measures in Sport-specific Training
}

\author{
Zheng Yong \\ College of physical education, China West Normal University, NAN CHONG, CHINA \\ zhengyong7867@163.com
}

Keywords: Sport-specific training; Track and field athlete; Ankle injury; Reasons.

\begin{abstract}
Objective: To observe and investigate the cause and the prevention measures of sportspecific training in track and field athletes ankle-joint injury, thus to provide a scientific basis for sports injury prevention and treatment. Methods: We randomly selected 200 track and field athletes in a school of grade 2013 and 2014 total; using statistical methods to track and field athlete injury occurrence are analyzed. Results: Through the investigation and analysis, a total of 65 athletes in sports injury, the incidence of sports injury was $32.5 \%$, the injury has something to do with age and sports life of athletes, but there was no statistically significant difference, $\mathrm{P}>0.05$; The part of the sports injuries are mainly ankle and thigh muscle, $35.38 \%$ and $30.77 \%$ respectively; The body fatigue, poor physical quality, technical master is a major cause of injuries are skilled. Conclusion: In order to reduce sports injuries, and enhance the life of the movement of athletes and sports ability, in the process of athletes training and exercise in the future, pay special attention to prolong athletes preparing activities, improve the standardization of the action, reduce the technical error and correct planning exercise.
\end{abstract}

\section{Introduction}

Athletics is the mother of movement, it is to compete and exercise by people walking, running, jumping, and venture of physical exercises, and it is the foundation of all sports. However, due to increasing the difficulty of the track and field technique, training time lengthened, the body's ability to also put forward higher request, therefore, for most high level athletes in track and field sports, sports injury is inevitable, and how to reduce the occurrence of sports injury is an important subject in front of the sports workers. College track and field athletes generally have good physical qualities and special skills, this is after many years of scientific training of the system, due to the occurrence of sports injury, however, not only broke the scientific system of training plan, also led to a number of promising athletes prematurely left the athletic field, which seriously hindered the development of track and field sports level. Thus strengthen the track and field athletes, especially the scientific understanding of high level track and field athlete injury, reduce the occurrence of sports injury and ensure high level athlete culture in colleges and universities, the special double harvest, seeking ways and means to effectively prevent the sports injury is imminent. Randomly chosen 200 track and field athletes in a school of grade 2013 and 2014 total, using statistical methods to track and field athlete injury occurrence are analyzed.

\section{The Objects and Methods}

The Object. We randomly selected 200 track and field athletes in a school of grade 2013 and 2014 total, using statistical methods to track and field athlete injury occurrence are analyzed. Age range is from 16 to 25 years old, the average age of 19.2 years, 132 men $(66.0 \%)$, female, 68 (34.0\%).

Method. By using the literature material law, the literature review about the sport injuries of track and field related literatures, the self-designed questionnaire, by trained investigators, to extract the 200 track and field athlete's gender, age, sport, fixed number of year of the injury, sports, sports level and other basic situation investigation, investigation content includes in the past by the type of sports injury, sports injury, sports injury occurred, and so on and so forth. 
The Statistical Methods. Access to consultation, investigation, collects the resulting data effectively, according to the principle and method of sociological statistics, on the computer use EXCELL and SPSS19.0 statistical software for analysis.

\section{Results}

The Happening of Sport Injuries of Different Gender. In 200 track and field athletes, male 132, female 68, 66.0\% and 34.0\% respectively. 200 track and field athletes, a total of 65 athletes in sports injury, the incidence of sports injury was $32.5 \%$.

Table 1 The happening of sport injuries of different gender

\begin{tabular}{llllll}
\hline Gender & $\begin{array}{l}\text { The number } \\
\text { of survey }\end{array}$ & $\begin{array}{l}\text { The number } \\
\text { of sports } \\
\text { injuries }\end{array}$ & $\begin{array}{l}\text { The } \\
\text { incidence of } \\
\text { injury }\end{array}$ & $\chi 2$ & P value \\
\hline Male & 132 & 42 & 31.82 & 0.162 & $>0.05$ \\
Female & 68 & 23 & 33.82 & & \\
Total & 200 & 65 & 32.50 & & \\
\hline
\end{tabular}

The Happening of Sport Injuries of Different Fixed Number of Year of the Movement. Sports injuries and the fixed number of year of the movement of athletes, but there was no statistically significant difference, $\mathrm{P}>0.05$ ).

Table 2 The happening of sport injuries of different fixed number of year of the movement

\begin{tabular}{llllll}
\hline $\begin{array}{l}\text { Years of the } \\
\text { movement }\end{array}$ & $\begin{array}{l}\text { The number } \\
\text { of survey }\end{array}$ & $\begin{array}{l}\text { The number } \\
\text { of sports } \\
\text { injuries }\end{array}$ & $\begin{array}{l}\text { The } \\
\text { incidence of } \\
\text { injury }\end{array}$ & $\chi 2$ & P value \\
\hline$<3$ & 38 & 11 & 28.95 & 0.728 & $>0.05$ \\
$3 \sim 6$ & 76 & 24 & 31.58 & & \\
$6 \sim 9$ & 52 & 18 & 34.62 & & \\
$>9$ & 34 & 12 & 35.29 & & \\
Total & 200 & 65 & 32.50 & & \\
\hline
\end{tabular}

The Parts of Player Injury Situation Analysis. The part of the sports injuries are mainly ankle and thigh muscle, $35.38 \%$ and $30.77 \%$ respectively.

Table 3 Athletes' injury situation analysis

\begin{tabular}{lll}
\hline Damage parts & Number & $\begin{array}{c}\text { icidence of } \\
\text { injury }\end{array}$ \\
\hline Ankle joint & 23 & 35.38 \\
Knee joint & 6 & 9.23 \\
Thigh muscle & 20 & 30.77 \\
Calf muscles & 16 & 24.62 \\
Total & 65 & 100.0 \\
\hline
\end{tabular}

The Cause of the Track and Field Athletes Ankle-joint Injury. The body fatigue, poor physical quality, technical master skillfully is a major cause of injuries, accounted for $24.62 \%$, $18.46 \%$ and $24.62 \%$ respectively. 
Table 4 The cause of the track and field athletes ankle-joint injury $(\mathrm{N}=65)$

\begin{tabular}{|c|c|c|c|}
\hline Ranking & Damage reason & $\begin{array}{l}\text { Case } \\
\text { number }\end{array}$ & $\%$ \\
\hline 1 & Physical fatigue & 16 & 24.62 \\
\hline 2 & $\begin{array}{l}\text { Physical quality is } \\
\text { poor }\end{array}$ & 12 & 18.46 \\
\hline 3 & $\begin{array}{l}\text { Master not skilled } \\
\text { technology }\end{array}$ & 9 & 13.85 \\
\hline 4 & $\begin{array}{l}\text { Preparation } \\
\text { activities is not } \\
\text { reasonable }\end{array}$ & 6 & 9.24 \\
\hline 5 & $\begin{array}{l}\text { Clothing shoes } \\
\text { and ground } \\
\text { equipment }\end{array}$ & 5 & 7.69 \\
\hline 6 & $\begin{array}{l}\text { Hurt to participate } \\
\text { in training and } \\
\text { competition }\end{array}$ & 5 & 7.69 \\
\hline 7 & $\begin{array}{l}\text { Local heavy } \\
\text { burden }\end{array}$ & 4 & 6.15 \\
\hline 8 & $\begin{array}{l}\text { Concentration in } \\
\text { the clouds }\end{array}$ & 4 & 6.15 \\
\hline 9 & Other & 4 & 6.15 \\
\hline Total & & 65 & 100.0 \\
\hline
\end{tabular}

\section{Conclusions}

\section{The Reason Analysis}

The physiological factors

According to the needs of research, this study thought physiological cause of sports injury old injury has not healed the body fatigue, insufficient muscle strength, endurance, insufficient flexibility, agility, etc. Body fatigue is caused in the physiological factors of the sport injuries of track and field is the most important factor, this is because when the body movement in due time, the working ability of human body each organs will temporarily reduce, whole body fatigue, this time without rest, fatigue is the continuous accumulation, leading to excessive fatigue, beyond the capability of the body organs are and there will be a sports injury; Therefore, coaches should pay more attention to the body fatigue caused damage, in the usual training to strengthen the learning theory knowledge, make full use of modern scientific knowledge, the use of reasonable recovery means and modern science and technology, enhance medical supervision and self supervision, reasonable arrangement of the amount of exercise and intensity of exercise, as much as possible to reduce fatigue and cause athletes to the occurrence of sports injury.

Old wound did not heal physiological factors caused the sport injuries of track and field is the second largest factor, this is due to the old wound did not heal, athletes part no attaches great importance to the athletes recover after injury, they think that minor injuries don't delay training, without considering the injured cannot achieve a high level of physical functioning after the training requirements, at this time to stay in the normal training or competition, will cause a new injury, therefore, in the process of training game, the coach must be carefully or prohibit old wound did not heal athletes continue to participate in training or competition, to avoid the old wound not good seasons adds new mark.

Muscle power shortage is caused in the physiological factors of the sport injuries of track and field, the third largest factor, muscle strength is the foundation of all physical quality, when athletes in training or competition, to accomplish the training plan or competition must rely on their own to overcome the body muscle contraction external force such as gravity, air resistance, if the muscle strength is not strong, is certainly will affect the action, the completion of quality and technical 
control also may lead to the occurrence of sports injury, as a result, athletes and coaches should fully realize the importance of quality of muscle strength training, combining with the characteristics of sports, have a purpose in a planned way of training good quality of muscle strength, reduce sports injuries caused by insufficient muscle strength.

Lack of flexibility is caused in the physiological factors of the sport injuries of track and field's fourth-largest factors, flexible quality is on the direction of human body joints in different dimensions and athletic ability (or range), and the extension of the soft tissues such as muscle, tendon and ligament. If athletes' flexibility can reduce the occurrence of sports injury, as a result, the coaches and players should pay more attention to the flexibility of practice, in the usual training in the process of scientific training methods to strengthen the flexibility of practice.

The psychological factors

According to the needs of research, this study considered sports injury caused by psychological factors have depressed when training or competition, training or competition seemingly too high, poor concentration, ego to protect consciousness.

Therefore, depression is caused when the training or playing the sport injuries of track and field, the most important factors of psychological factors that's because due to the large training load in the process of training or competition, the athlete's body have lead to athletes psychological injuries have conflicts or boredom, but had to obey the arrangement of the coach, so against their will and adhere to the training or competition, but the low mood will cause the loss of athletes distraction, response sensitivity, distance disappear, thinking and tactics of the phenomenon such as poor consciousness, confusion of offensive and defensive moves, so will inevitably lead to deformation of action that lead to the occurrence of sports injury, therefore, in the process of training or competition, the athletes coaches should always focus on the athletes' physical and psychological tendency, and athletes are often thought of communication, know more about the inner world of athletes, improve the athletes' psychological ability to adapt. Athletes also should timely adjust their own state of mind, listen to music, edify their sentiment more at ordinary times, and learn to turn their low mood adjustment to the active state.

Inattention is the sport injuries of track and field caused by the psychological factors of the 2nd big, this is due to the track and field sports is mainly rely on activists own physical quality for training or competition, and track and field is more complex, the technique of each projects need athletes highly concentrated, if distracted, is bound to affect the quality of the action completion, operation is completed quality is bad and likely to be sports injury, therefore, in the process of the usual training or competition, the athletes must strengthen the attention ability, strengthen their antiinterference ability, form the habit of attention, consciously overcome their own emotional, improve the level of emotional excitement, adjust their own state of mind to the best level, reduce the occurrence of sports injury.

Training or competition seemingly high sex is the third in the sport injuries of track and field caused by psychological factors. Euphoria will lead to athletes and coaches were wrong, and make the action quality is affected, causing injury. Therefore, in the process of training or competition, the coaches should pay close attention to the athletes' psychological dynamic at any time, and its communication, timely give athletes psychological adjustment, correct judgment of its psychological world, adjust the training plan, reduce the occurrence of sports injury; Athletes themselves in the process of training or competition also to adjust their own state of mind, to keep their excitability in the best condition, excited neither difficult to suppress, and don't feel depressed, and finishing of high quality technology, reduce the occurrence of sports injury.

Poor ego to protect consciousness is the fourth in the sport injuries of track and field caused by psychological factors. Ego to protect consciousness is to point to in the process of training or competition, when an emergency or sports injury comes, athletes on the thought and behavior are prepared ahead of time, is a reflection of the comprehensive quality players. Therefore, in the process of training or competition, the coaches must according to different projects, the technical features carefully study the purpose, make the athletes understand the physiological structure of the body, so they can know according to the characteristics of every training session and content prone to damage, prepared to prevent in advance, improve the ego to protect consciousness, when there is an emergency can reduce the occurrence of sports injury.

The technical factors 
According to the needs of research, this study considered sports injury caused by technical factors each other foul action, technology is not skilled, skilled action errors, lack of self-protection actions, etc.

Technology is not good at track and field athlete sports injury caused by technical factors, the most important factors of track and field technique was formed by follow the principle of structure and mechanics, the technology is not skilled bad is bound to produce physical and psychological state, therefore, in the process of track and field training or competition, to make the athletes of mastering techniques, try to avoid the occurrence of sports injury.

Technology is motion error caused the sport injuries of track and field technical factors of the 2nd big factors. Technical error is refers to the athlete not master the skill movements of the right, the use of wrong action violates the law of the structure and movement of the body, prone to sports injury during training or competition. Accordingly, when athletes in training or competition, must learn the correct technique, to master the correct technical main point, in view of the error-prone actions must repeatedly research, pay attention to every link of technical action, repeat practice more; Coaches to athletes, the technique of correct action in time, make its master the skill movements of the right, not only can prevent the occurrence of sports injury, also can effectively improve the ability of competitive sports.

Lack of self-protection actions caused the sport injuries of track and field technique is the third big factors. Lack ego to protect action refers to the athletes lack protection consciousness, in the process of training or competition, when an emergency or sports injury comes, not athletes take corresponding preventive measures to protect them. Therefore, in the process of track and field training or competition, the athletes should constantly strengthen their own protection consciousness, purposeful training their ability to prevent, coaches should also be targeted training the athletes' ego to protect ability, reduce the occurrence of sports injury.

A foul action causes the sport injuries of track and field technique is the fourth big factors. Only $4.1 \%$, this is because the relative to other sports, track and field belongs to individual competitive projects rather than fierce antagonism, this greatly reduce collisions with other athletes physical contact or confrontation, avoid the happening of the damage to a certain extent, but in the process of training or competition, also a foul and a collision happens, such as relay race, hurdle, etc.

The training factors

According to the needs of research, this study thought training cause of sports injury has hurt training game, partial burden, inadequate preparation, sports load is too large, recovery time and arrangements unreasonable, etc.

"Accordingly, inadequate preparation is the most important factors causing the sport injuries of track and field training. Preparation activities is refers to the athletes in training or competition activities, in order to make the body gradually enter the work state, make body and mind as the main body activity to prepare a series of physical exercises and activities. Preparation activities are, therefore, in order to overcome the visceral organs such as the function of the body before training or competition inertia, improve cerebral cortex excitability of the nervous system, make human body each organs by static into nervous activity state as soon as possible, in order to meet the requirements of training or competition, for the upcoming training or competition ready to physical and mental, is the function of human body each organ, system's biggest work efficiency, increase the flexibility of the joints in order to meet the intense exercise the friction, torsion, reduce the occurrence of injury. However, if insufficient preparation, no mobilize to participate in the training of organ systems, it is bound to affect the work efficiency of each system function the flexibility of joints, muscles, ligaments and the extension is affected, it could cause injury. Therefore, coaches must supervise athletes actively prepare activities; athletes themselves also want to prepare activities, as far as possible to reduce the occurrence of sports injury.

Recovery time and arrangements unreasonable causes the sport injuries of track and field training are the second largest factor. Training process is a repeated body structure and function of destruction and reconstruction process. Through load movement, consume a large amount of energy material; cause the fine structure of a certain degree of damage, and internal environment disturbance, etc. Then in the recovery period, using the body with the adaptability features, structure and function of the reconstruction, make exercise capacity has been improved to a certain. But it takes a while for the reconstruction of the structure and function of process. If the next training under the recovery is 
not completely, then the body is not yet complete reconstruction process, not only cannot improve exercise capacity, it will increase the damage degree of micro structure, resulting in injury. Therefore, in the process of training or competition, the coaches must be reasonable arrange exercise program, must take the appropriate recovery measures after training, to make the athlete skill levels back to his best, and the recovery of athletes themselves also should actively, strive to make their own body at the next level of training to get a better state, reduce the occurrence of sports injury.

Motor overload causes the sport injuries of track and field training is the third largest factor. Excessive exercise load is the body in the process of sports more than the body can withstand physiological stimulation; it will cause the body to drop, lead to physical fatigue, make a lot of lactic acid accumulation in the body, affecting the flexibility of joints and ligaments, causing the damage occurred. Therefore, in the process of training or competition, the coaches must be reasonable arrangements for the amount of exercise and intensity of movement, prevent excessive exercise load caused the occurrence of sports injury, the athlete will according to your own physical condition timely adjust their exercise and exercise intensity, reduce the occurrence of injury.

Local burden is causing the sport injuries of track and field training of the fourth big factors. Local burden is due to the training plan or training content arrangement is not science, resulting in body movement caused by fatigue damage. Coach in the training plan, therefore, should be aimed at individual differences, aiming at different levels and different levels of the athletes for their training plan. Wounds caused the sport injuries of track and field training game is the fifth largest factor in training factors. Training game not only won't hurt by the good training effect, instead will increase damage condition, cause new damage, thus affecting the entire training program, so the coaches and athletes themselves must realize the seriousness of the wounded training game, in the process of training or competition, you must see to it that old wounds heal completely, make the athletes body function are suitable for training or competition, reduce the occurrence of sports injury.

\section{The Preventive Measures}

The attaches great importance to the preparatory activities, strengthen the protection of the vulnerable parts

The reasonable preparation activities, can make the rapid improvement of the central nervous system excitability, accelerate blood circulation, decrease muscle ligament between the viscosity, but also can increase the extension of joint ligament, improve the function of the body organs, improve the sports ability of stress. Therefore, reasonable preparation activities not only can make the body gradually enter the work state, reduce the inertia of muscle activity, improve sports ability, also can reduce the occurrence of sports injury.

The scientifically arrange training content

Coaches should reasonably arrange the training content, and to adjust according to the athletes' mental state, the arrangement of the training content should reflect the scientific nature, to step by step, gradually improve, avoid the local burden, the volume is too big, body fatigue, muscle strength is insufficient, excessive exercise load on the state. In the movement, the human body to produce adaptability and the intensity of training. This is because, the improvement of the human body movement ability is implemented through a series of stimuli, to achieve better results, must be the stimulation of a higher level, however, everything must have a degree, is stimulated the body's ability to also have certain limits, not exercise intensity or the greater the amount of exercise, the better, therefore, the coaches in training athletes should fully consider the physiological characteristics of the individual, the arrangement of the scientific exercise load.

The strengthen medical supervision and institutionalized management

Many athletes and coaches for lack of medical supervision, resulting in some athletes after an injury not timely diagnosis and treatment, which can lead to some athletes are training or competition with, increase the sports injury happening again and, therefore, to strengthen health supervision, establishing institutionalized management, establish a strict, scientific, perfect medical supervision system, coaches and physicians, a psychologist, scientific research personnel should according to the actual circumstance of the athletes' personal, work out the reasonable training plan, arrange rehabilitation sports, step by step in a planned way carefully and patient rehabilitation training.

The notice fatigue recovery and dietary nutrition 
Many projects of track and field sports with athletic intensity big, the high speed, great physiological load of exercise, athletes with high strength and great physiological load of exercise training, if measures are not taken effective recovery is easy to cause the accumulation of fatigue, can cause excessive fatigue and local carry momentum is too big, resulting in the occurrence of sports injury. Therefore, after training or competition, the athletes should pay special attention to the recovery of the fitness and nutrition supplement, get plenty of sleep, on the basis of the trace elements and mineral supplements, can eat some fresh vegetables and fruit more, is advantageous to the movement to eliminate accumulation of acid in the process of product. In addition, players can also according to the condition to carry on the massage, sauna and the in the mind to relax, etc., which not only can accelerate the recovery of fatigue, prevent the happening of the damage, and for the future training and competition to improve security.

The strengthen athlete ego to protect consciousness

Strengthen the athletes' ego to protect consciousness, ego to protect consciousness is to point to in the process of training or competition, when an emergency or sports injury comes, athletes on the thought and behavior are prepared ahead of time. Therefore, in the process of training or competition, the coaches must according to different projects, the earnest study of the characteristics of track and field projects technology, make the athletes understand human physiological structure, so they can know according to the characteristics of every training session and content prone to damage, prepared to prevent in advance, improve the ego to protect consciousness, when there is an emergency can reduce the occurrence of sports injury.

\section{References}

[1] Kim L. Bennell, Susan A. Malcolm, Shane A. Thomas, Peter R. Ebeling, Paul R. McCrory, John D. Wark, Peter D. Brukner. Risk Factors for Stress Fractures in Female Track-and-Field Athletes: A Retrospective Analysis[J]. Clinical Journal of Sport Medicine. 2013 (4).

[2] Tomoko Okada, Kellie C Huxel, Thomas W Nesser. Relationship Between Core Stability, Functional Movement, and Performance[J]. Journal of Strength and Conditioning Research . 2013 (1).

[3] Kate I Minick, Kyle B Kiesel, Lee Burton, Aaron Taylor, Phil Plisky, Robert J Butler. Interrater Reliability of the Functional Movement Screen[J]. Journal of Strength and Conditioning Research . 2013 (2).

[4] Virginia S. Cowen. Functional fitness improvements after a worksite-based yoga initiative[J]. Journal of Bodywork \& Movement Therapies . 2014(1).

[5] Ghoreishi, S Amir,Nekoui, Mohammad Ali,Partovi, Saeed,Basiri, S Omid. Application of Genetic Algorithm for Solving Multi-Objective Optimization Problems in Robust Control of Distillation Column[J]. International Journal of Advancements in Computing Technology . $2011(1)$

[6] Jaffar Rasool,Keith George. The impact of single-leg dynamic balance training on dynamic stability[J]. Physical Therapy in Sport . 2012 (4)

[7] G. Millet,R. Candau,B. Barbier,T. Busso,J. Rouillon,J. Chatard. Modelling the Transfers of Training Effects on Performance in Elite Triathletes[J]. Int J Sports Med. 2012 (01)

[8] E. W. Banister,J. B. Carter,P. C. Zarkadas. Training theory and taper: validation in triathlon athletes[J]. European Journal of Applied Physiology and Occupational Physiology. 2012(2)

[9] JEAN-CLAUDE CHATARD,XAVIER SENEGAS,MICHEL SELLES,PATRICK DREANOT,ANDRE GEYSSANT. Wet suit effect: a comparison between competitive swimmers and triathletes[J]. Medicine \& Science in Sports \& Exercise . 2012 (4)

[10]Marlene Beaulieu,Paul Allard,Martin Simoneau,Georges Dalleau,Fuad A. Hazime,CharlesHilaire Rivard. Relationship Between Oscillations About the Vertical Axis and Center of 
Pressure Displacements in Single and Double Leg Upright Stance[J]. American Journal of Physical Medicine \& Rehabilitation . 2013 (10) 